International Journal of Management Science and Business Administration

Volume 3, Issue 5, July 2017, Pages 7-20

DOI: $10.18775 /$ ijmsba.1849-5664-5419.2014.35.1001

URL: http://dx.doi.org/10.18775/ijmsba.1849-5664-5419.2014.35.1001

\title{
The Advantage of Digital Decision Making for Strategic Decisions - Proofed by a Supply Chain Case
}

\author{
Steffen Hossfeld \\ School of Management, University of Latvia, Riga, Latvia
}

\begin{abstract}
This paper will discuss the advantage of decision making supported by a digital system and will provide an overview of an empiric analysis researched on this topic. Decision making in organizations is a significant system implied task of managers and therefore a broad area in scientific research, not only in the disciplines management or business studies - even from technical to humanistic disciplines. Nowadays the trend of digitalization captures all areas of life especially in business, as well as the typical management task of decision making. Triggered by the digitalization trend business will move toward an autonomous decision making of machines or cyber systems. The important step toward autonomous decisions or decision support (cyber systems will prepare a decision, but finally executed by a human) will be the next development step for decision making. Designed algorithmic models for these decisions will use the content of classical decision models to reach maximum utility. Hence, a view on classical decision making will illuminate the basis for these models, from researchers like von Neumann/Morgenstern or Bernoulli. Furthermore, digitalization changes the process of decision making, especially focussing on the behavioral part of decisions, discussed from Simon, Selten or Tversky/Kahneman. Due to reason that today the human aspect of decision making is sustainable in organizations. The hypothesis that the digital set up for decision making in organizations will increase the efficiency of strategic decisions will be proofed by an empiric study. The research method for the empirical part of this paper is a questionnaire. It is online questionnaire which will be answered by professionals and scholars. As a typical example of a strategic decision, the author explains a business case in the supply chain function of organizations. A section of the well-known SCOR model will be tested on digitalization characteristics. The research findings of the questionnaire will illustrate that the digitalization of supply chain processes is in the scope of managers and consultants, to reach higher efficiency by increased turnover or by reducing costs. The result of this paper verifies an improved decision process by usage of digital features, but the capability of the entire digital possibilities is not fully achieved yet.
\end{abstract}

Keywords: Decision Making, Digitalization, Empirical Analysis

\section{Introduction}

Nowadays the megatrend of digitalization creates new challenges for the entire business environment. These changing elements enforce organizations to reconsider their way of doing business, even to rethink their entire business model. Digitalization is today and will be in the future a key driver for change in organizations and especially the process how decisions will be made. IT leadership, as one important function in an organization, is currently forced to make major changes, as digitalization of products and services is transforming traditional business models across industries. IT is no longer merely an internal corporate function that provides services for the organization's employees, but IT services are becoming embedded into sellable products and services, too (Collin J., 2015). In this new context, the focus on the wide area of decision-making theory is quite important, from a more rational view to a more emotional view. Analyzing decision making through the view of digitalization, completely new opportunities and approaches will appear in a close future. Setting the scene for the current state, a questionnaire was made with business and scholar professionals to understand the lack of opportunities and execution level of organizations. The strategic decision area of supply chain seems to be a fascinating field for research. The SCOR model is an accepted model of scholar and business, hence worth to be analysed. 


\section{Theory of Digitalization and Decision Making}

"Digitalization refers to the practice of taking processes, content or objects that are used to be primarily (or entirely) physical or analog and transforming them to be primarily (or entirely) digital. The effect of digitizing processes, aside from potential efficiency gains, is to make processes more tailorable and malleable" (Fichman R., 2014). Not only based on data, moreover targeted on markets, organizations and processes digitalization will also deploy its full value to businesses and industries. The new era of digitalization has already started and shows the first step of a new business world with a change in the division of work. In the early 20th century a "computer" was an employee calculating tables the whole day. In a first step, an automated computer (as we understand today) took over this task and increased quality and efficiency of this process. Since then, the automation of our world was ongoing and influenced by computers and machines. Crucial for the development was the definition of rules for computers because computers are perfect in following algorithmic rules. (Brynjolfsson E. and McAfee A., 2014). Further actions took place to develop more feasibilities of machines, i.e. Apple iPhone is now with the software Siri able to understand and direct the user. It is a real quantum leap because language automatization and transformation of it into instructions was a giant step for the industry. Currently, the speed of development is increasing, either the trend of "Industry 4.0" with full automation of the production flow (Zelinski P. 2016) or "artificial intelligence" that robots tend to make autonomous decisions and developed self-awareness and self-maintenance (Lee J. 2014).

Referring to the effects of digitalization, this trend will completely change the way of making business and making decisions. Flexibility and transformability are key attitudes of successful organizations in the future and drive them on the road of digitalization (Bauer W., 2015). Digitalization will have an effect on customer structure and behavior, increase the efficiency of operations including their supply chain and at the end may change the entire business model. (Westerman G., 2014). It is important to understand the logic of digitalization and to realize the four levels of transformation. These four levels have to be in scope of the decision maker (BDI, 2015)

\section{Digital data (big data)}

Due to recording, processing and analysis of mass data, high-quality and more predictable forecasts and decisions are possible in organizations. The structure of big data is (Goes P., 2014):

- Volume: measured in Giga- or Terabyte

- Velocity: One-time snapshot frequency streams

- Variety: structured, numeric, alpha, unstructured, text, voice / sound, image / video, genomics

-Veracity: Validation, noise level, deception, detection, relevance, ranking

Big data is a huge trend in digitalization because the usage of data is important for an organization. As "the economist" wrote in 2010, "Data are becoming the new raw material of business." And data are increasing day by day. A strong increase of data traffic had happened and will further increase; in the future driven by digitalization, e.g. machine to machine communication or the trend of mobile data from every user of the internet. This traffic is permanently increasing, and all devices are moving toward mobile and smart functions. The latest trend of data shows the movement from big to smart data which means data including utility, semantics, data quality and security (S. Jähnchen, 2015)

\section{Automation}

The traditional trend of automation is an ongoing process pushed by new technology and the need for efficiency to enable a competitive cost base. The combination of traditional work and technology with artificial intelligence will enable autonomous work in self-organization systems with high quality and high efficiency. As an effect, production speed will increase and unit costs will drop. Automation has different aspects of realization. First, the work volumes between man and machine are changing. Second, the trend toward a higher automation is still ongoing, up to entire fully automated factories without human beings. Today a work flow from machine to machine without human interaction is possible and works without variances on a repeatable high-quality level. The third step, artificial intelligence, is a self-learning system, with a set of different reactions based on environmental conditions. As an example, one new technological process is rapid manufacturing, which means that traditional production types will be replaced by new technology. This new technology uses direct digital data for production, without a tooling procedure. Cost intensive tools are replaced by new manufacturing applications. These procedures are very flexible at an acceptable cost level and permit small batches. 3D printers are today on a level beyond testing and started their usage in business. Different possibilities of 3D printing enable a wide range of applications. (Bopp F. 2010). 


\section{Integration}

Connecting the entire value chain by the high-quality broad band will enable synchronized supply chains with shorter production cycles and faster innovation cycles (mobile or fiber opic net).An important integration in the era of digitalization is a deeper collaboration in the entire supply chain. Based on a more flexible consumption behavior a more agile supply chain has to deliver this flexibility. As a result, a strong cross-company collaboration is a must, and online information has to be exchanged between the different entities. Cross-linking of organizations and their IT systems are the requirement for an efficient supply chain. Today's technology enables this process, based on standard software tools and open interfaces for an optimal data exchange between them. A fast changing world, with a drop in product life cycles, the integration between supplier and customer has to be on the level of a partnership because a cross-company product development process needs to have speed in "time to market" on a cooperative relationship. (Wannenwetsch H. 2007) .

\section{Digital customer access}

New competitors, new services, and new transparency will increase competition and market position of companies and brands. For customers, the next opportunity is just one click away. Hence a well thought out strategy is necessary to position against competition, no matter from which industry it's coming from. For the car manufacturer BMW the competitor isn't anymore only Audi or Daimler, now it's Tesla and Google, with their new approach to mobility. (Brynjolfsson E. \& McAfee A., 2014). The consumer and customer is again back in the center of scope of organizations. In the recent years, consumer behavior and hence customer activities changed dramatically toward a less loyal, more flexible and quick response relationship. Increased mobile services, e.g. via smart phone increased this trend, and Kreutzer/Land described the consumer buzzwords as follows: "me, all, immediately and everywhere"; which is exhibited in table 1 "Customer Expectation: Me, all, everywhere and immediately".

Table 1: "Customer Expectation: Me, all, everywhere and immediately” (Kreutzer R. \& Land KH. 2015)

\begin{tabular}{|l|l|l|l|}
\hline Me & All & Everywhere & Immediately \\
\hline Appreciation as must & Wide choice & Time independence & Instant contacting \\
\hline $\begin{array}{l}\text { (correct) } \\
\text { Personalization }\end{array}$ & High quality & $\begin{array}{l}\text { Location } \\
\text { independence }\end{array}$ & Fast transactions \\
\hline Tailored offers & Low prices & $\begin{array}{l}\text { Independence of } \\
\text { technologies, } \\
\text { channels, devices }\end{array}$ & Short response time \\
\hline $\begin{array}{l}\text { Approach based on } \\
\text { permissions }\end{array}$ & Good service & & \\
\hline
\end{tabular}

The mentioned customer expectations are increasing, but in today's flexible world, this expectation is covered by competition. Hence this has to be the mantra in an organization. The trend of "smartization" is still ongoing and will further move on, making all devices via networks intelligent. Starting with mobile phones, developed to smart phones, now we see smart TVs and smart watches. Also, housekeeping is going smart, with refrigerators or washing machines, even energy consumption is steered with smart technology (Kreutzer R. \& Land KH. 2015). As Porter describes, new smart products for consumers with three core elements: physical, smart and connectivity. All three elements deliver customer value improvements and are substantial for a future market position (ME Porter \& JE Heppelmann, 11/2014)

Decision theory is a wide area in science, with a long tradition. The first idea of decision theory reaches back over hundreds of years and is still relevant in the present. Rational models were discussed from the neoclassical economists (e.g. Adam Smith or Max Weber) with a view on rational behavior of agents which maximize their utility - the homo oeconomicus. A more scientific approach of Pascal and de Fermat shows a calculation of probabilities and Bernoulli laid the foundation of risk science by examining random events. Further developed by von Neumann/Morgenstern economic behavior in a strong rational and mathematical approach, decision making follows utility maximization. Today's view of decision theory as an interdisciplinary science (economics, psychology, sociology, philosophy, mathematics, computer science, and statistics) with different approaches is generally accepted (Buchanan L. and O'Connell A., 2006). The most popular theory is still the theory of games and economic behavior (von Neumann J. and Morgenstern O., 1944). The theory of von Neumann/Morgenstern explains a rational behavior of market participants (either consumers or entrepreneurs). Consumers strive for a maximum utility or satisfaction and entrepreneurs strive for 
maximum profits. Meanwhile, a wide area of mathematical approaches and models of rational theories were further developed on the foundation of von Neumann/Morgenstern theories. The opposite of the rational view is a behavioral view on decisions. In the late 1940ies, Simon discussed the theory of bounded rationality, which means a certain influence of human attitudes with not pure rational decisions (Simon H.A., 1997). A deeper view in the psychology science shows that theories on the behavioral economy are currently quite popular because human behavior is one part of organizational actions. In the 70ies Kahneman/Tversky developed the prospect theory. Also, Reinhard Selten contributed research to the field of behavioral decision making.

\subsection{Rational View}

In the classical field of the economical view on decision theory, a rational, mathematical founded approach is discussed. The process of pure calculating to find a maximum of utility or profit is a typical rational procedure. In the dimensions of decision fields, the alternatives are significant to analyze. There is only a decision problem if there are minimum two alternatives. Hence a determination of these alternatives must be reflected in the decision model. In the next step, an evaluation of these alternatives must be done. These consequences will lead to a result of the alternatives into the decision model. Important figures of the decision maker are defined as targets, these values are the result. (Laux H., 2014).

For a structured process, the environmental conditions are very important. Measures are not manipulable by the decision maker, these measures are called decision relevant data. These data are no variables for the decision maker. These characteristics are decision relevant environmental conditions. The illustration of figure 2 "Structures of Environmental Conditions" (Laux H., 2014) shows different environmental situations and a possibility of designing decision conditions.

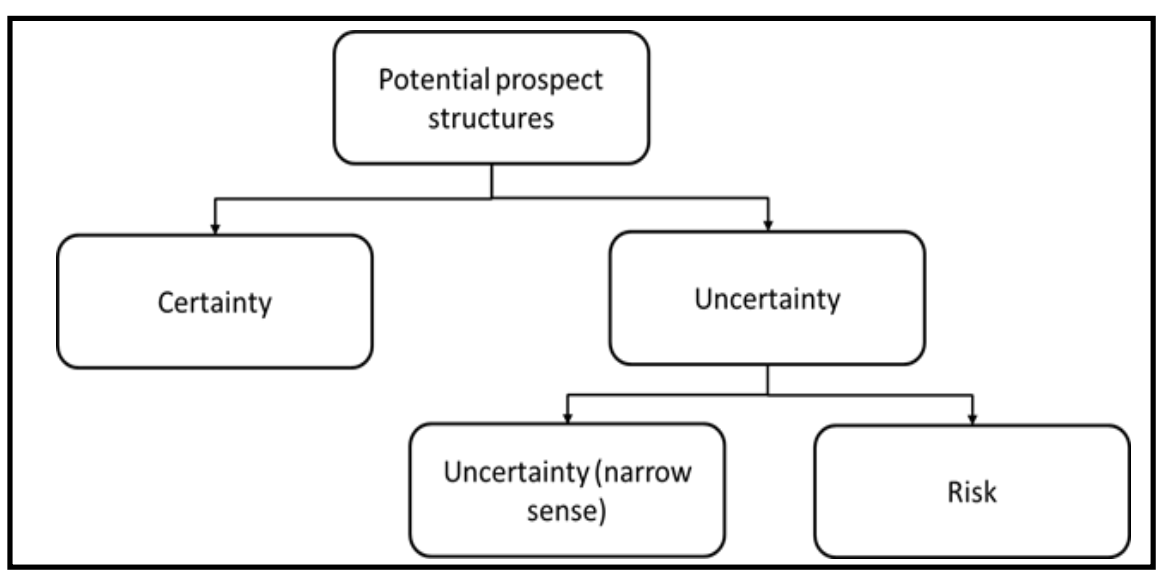

Figure 2. Structures of Environmental Conditions (based on Bamberg G., 2012)

A decision structure under certainty means, that the decision maker has the real condition of the alternatives, hence all relevant information for the decision is given. Therefore the result is known and alternatives are certain. In reality, quite often decision models are formed as models of decision under certainty because the setup and the usage of this model type is easier to handle (Bamberg G., 2012).

A decision structure under uncertainty means, that the decision maker has minimum two possible alternatives, but not all relevant information for a decision are given. Therefore the result is not known and alternatives are uncertain. In the case of uncertainty, there are two more possibilities. Either for the decision maker it's not possible to calculate a likelihood of conditions (uncertainty - narrow sense) or for the decision maker the probability of occurrence of a condition is computable (risk); (Laux H., 2014).

This differentiation of the environmental conditions is important to define; especially decision making in the context of globalization and digitalization. While globalization creates more complexity and uncertainty, a more sophisticated model for decision making is substantial for an organization. In terms of digitalization, a need for algorithmic structures is a must, computers need a mathematical logic to calculate a result for the decision. 


\subsection{Emotional View}

Significant developments in decision theory took place over the recent decades, though a trend to a behavioral approach was supported by psychological science. An outstanding contribution to the development of behavioral economics was made by Kahneman and Tversky. A collection of their scientific contribution and analysis is made in the book "Thinking, Fast and Slow" (Kahneman D., 2011). Describing decision theory with a strong psychological view makes a decision more emotional than rational. Depending on the activated system in the mind; Kahneman named it system 1 and system 2. "System 1 operates automatically and quickly, with little or no effort and no sense of voluntary control" (Kahneman D., 2011) Examples: answer of $2+2=$ ?; Drive on an empty road, orient the source of a sudden sound. "System 2 allocates attention to the effortful mental activities that demand it, including complex computations. The operations of system 2 are often associated with the subjective experience of agency, choice, and concentration." Examples are to tell someone your mobile number or fill out a form. The human structure is based on usage of system 1, only if necessary, system 2 is activated. (Kahneman D., 2011)

This concept of system 1 and system 2 set the basis for a human behavior of decision making, which absolutely defers from a rational decision view. Continuing this idea, the question what prevents a rational decision should be answered with Kahneman/Tversky's prospect theory. The fact that a lot of decisions have both elements, a risk of loss and an opportunity of gain, effects a decision to gamble or to deny. Focussing on loss aversion (Kahnemann D. and Tversky A., 1974) means, people avoid losses while there is a huge opportunity to gain this particular option. As a result, people deny this option and this is controversial to a rational choice, with a pure calculation of probability. On the other hand the "optimistic bias" means that chances for success are overestimated. Risks are undervalued or not in scope of the decision maker (Kahneman D., 2011).

Following the process, the maximum utility for the decision should be made. The main question is, if in an organization this strict process will be executed. As H.A. Simon explains, "all decision is a matter of compromise". In an organization with different interests of members, the question of a maximum utility for the decision problem is to be questioned. In an organization, there is never a perfect achievement of targets reachable. The environment of the organization limits the alternatives and the maximum of utility (Simon H.A., 1997). This opposite view to a rational decision process raises the question how the decision process in organizations is really made. Are organizations as rational as expected or are they emotional driven which have effects on decisions. The behavioral influence in organizations has to be respected and the result is based on this set up (March J. \& Simon H.A., 1993).

\section{Research Question and Hypothesis}

Taking the described topic into scientific context, the research question is asking for a relationship between an intelligent digital setup for decision making and the quality of the strategic decisions. The intelligent digital setup means a well-customized system for an organization which enables a more efficient process. The type of customizing has the respect the industry, customers and the organizational set up of a company because every single organization has its own perfect fit in a competitive system. A digital setup means all organization's procedures transferred into a digital context, either fully digital in machines or executed by a cyber physical system. The quality of the strategic decision has to be taken into context to the origin of the decision. A profit improvement is not necessarily an indicator of a quality increase of a strategic decision because not all strategic decisions are directly linked to profit increase vice versa sometimes profit happens by coincidental effects. The main hypothesis of this paper will analyse the dependency of the efficiency of strategic decisions and the digital set up for decision making in organizations (H0).

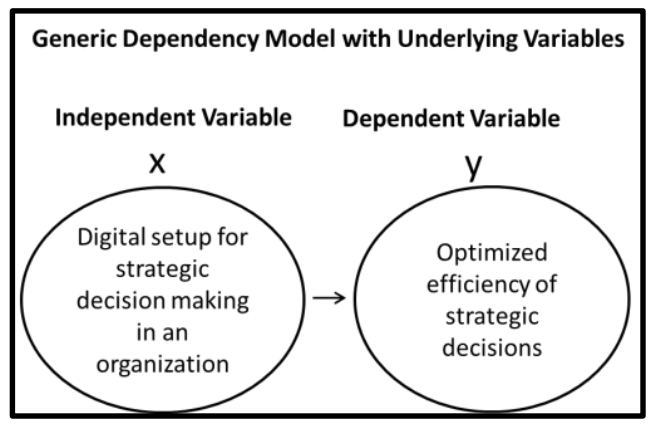

Figure 3. Generic Model of Digital Setup for Optimized Decision Making (designed by the author) 
The generic dependency model with the relevant variables is displayed in figure 3 and the basis for the subsequent research model. Based on the generic model, which has to be seen as an open model for various business cases, a more detailed model will be designed in the chapter "Research Model." In the generic model, the independent variable " $x$ " is the mathematical representative for "digital set up for strategic decision making in an organization" and the dependent variable " $\mathrm{y}$ " is the mathematical representative for "optimized efficiency of strategic decisions". To set the variable into relation, the following expression will be proved on validity:

- The more intelligent the digital setup for decision making of an organization, the better the quality of strategic decisions.

- The more human (manual) procedures for decision making of an organization, the worse is the quality of the of strategic decisions.

In the further analysis of the hypothesis, the generic model has to be set in context with a real business case, to make assumptions and the prove these hypotheses.

\subsection{Research Model}

The research model for this paper is based on the above mentioned generic model. As described, a supply chain business chase should be analyzed on its dependency between the variables of "digital setup for strategic decision making in an organization" and "optimized efficiency of strategic decisions". The different values of the variables itself are quite interesting, but also the dependency of the variables.

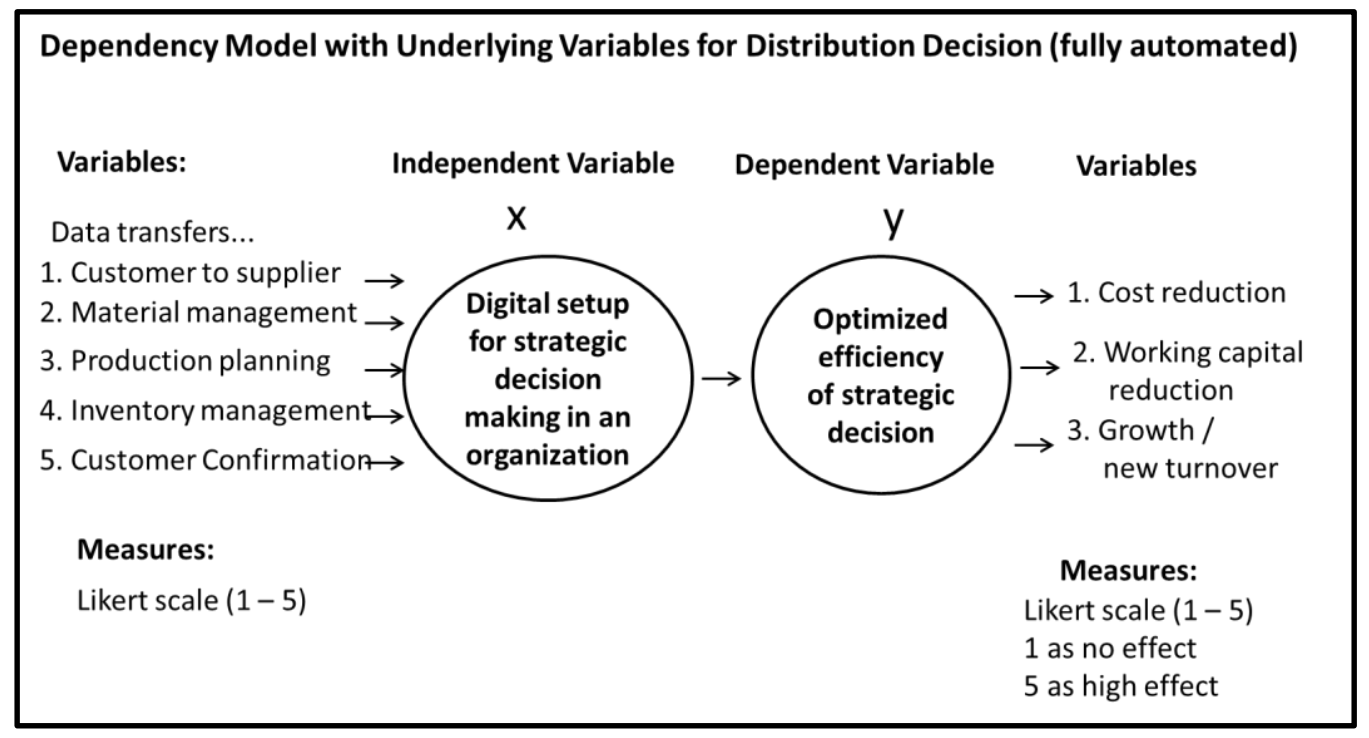

Figure 4: Dependency Model with Underlying Variables for a Distribution Decision (designed by the author)

The definition of the independent variables is, as described in figure 4, the digital process of data transfer from customer to supplier, then into the material management, production planning, and inventory management system. Followed by the customer confirmation if it's done on a defined digitalization level. For the dependent variable, the relevant values will be analyzed, from cost reduction over working capital reduction to turnover growth. For both variables, the characteristics will be analyzed in detail.

\subsection{Empirical Design \& Research Method}

For the empirical design and the research method, the above-described supply chain case is relevant. Gaining data in an appropriate approach more data ensure a higher quality of the conclusion, hence a questionnaire is a common tool to collect data for a statistical approach. The questionnaire structure is asking in the first part of personnel and organizational data of the interviewee. In the second part of the questionnaire the digital characteristics of the process and data flow will be asked ("a-section"). The "b-section" questions will ask in general for the decision type, either if the decision is completely automated (autonomous by cyber systems) or a decision support process (digital preparation of a decision and final human decision making). "c-section" and "d-section" are more general and are asking for the questionnaire style itself, if there are any remarks and the level of difficulty of the question. In the third part of the 
questionnaire, the goals and results of digital decisions have to be evaluated, to have the full picture of the research model.

This questionnaire will evaluate the digital characteristics of the supply chain process. Based on the SCOR model the selected process steps are customer forecasts and the subsequent activities until production will be analyzed. Participants have to answer if this process in their company is done digital or manual. After evaluation of the kind of data processing, the goal for the digitalization will be analyzed. The key question for an organization is the strategic scope - more cost or revenue driven. The SCOR model describes the type of interaction between suppliers and customers, as shown in the following chart. For this questionnaire, only the planning and sourcing part will be analyzed. It means forecasting of customer demand and availability of products and production opportunities are in the scope of this questionnaire.

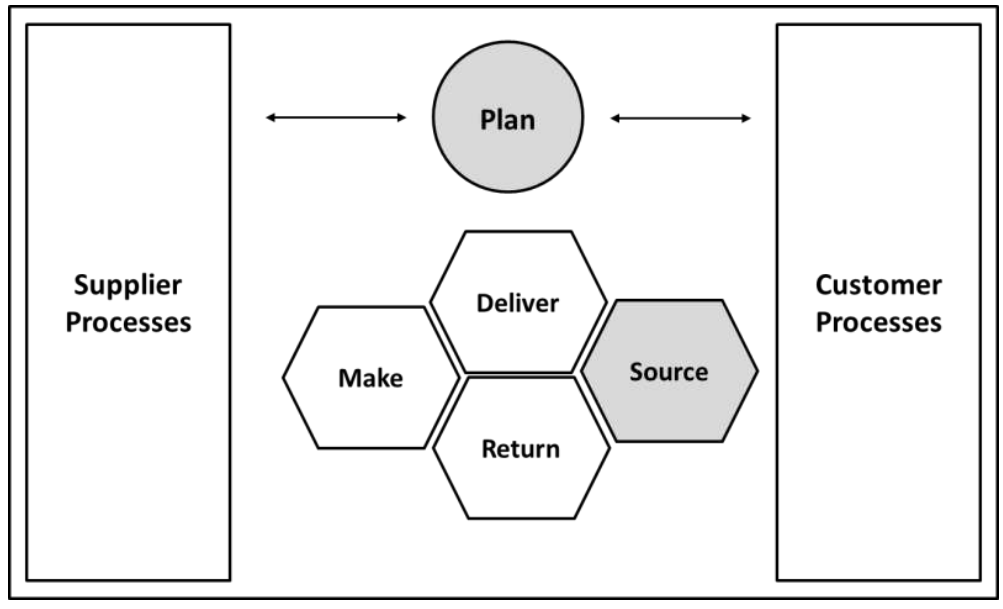

Figure 5: SCOR Model (based on Bolstorff P. \& Rosenbaum R. 2007)

The distinction between „Manual" and „Digital" will be defined as follows. „Digital" means that data processing will be done automatically without manual or human interaction. „Manual" means, that manual or human interaction is necessary to process data further in the workflow. If the process consists of both parts, please estimate in the given categories. "Decision support" means, a proposed result is automatically calculated, but a manual approval (human interaction) is required to finalize the process step. „Decision automated" means that a decision is made by a machine without further human interaction. The SCOR model as a description of supply chain processes in business is relevant and well known.

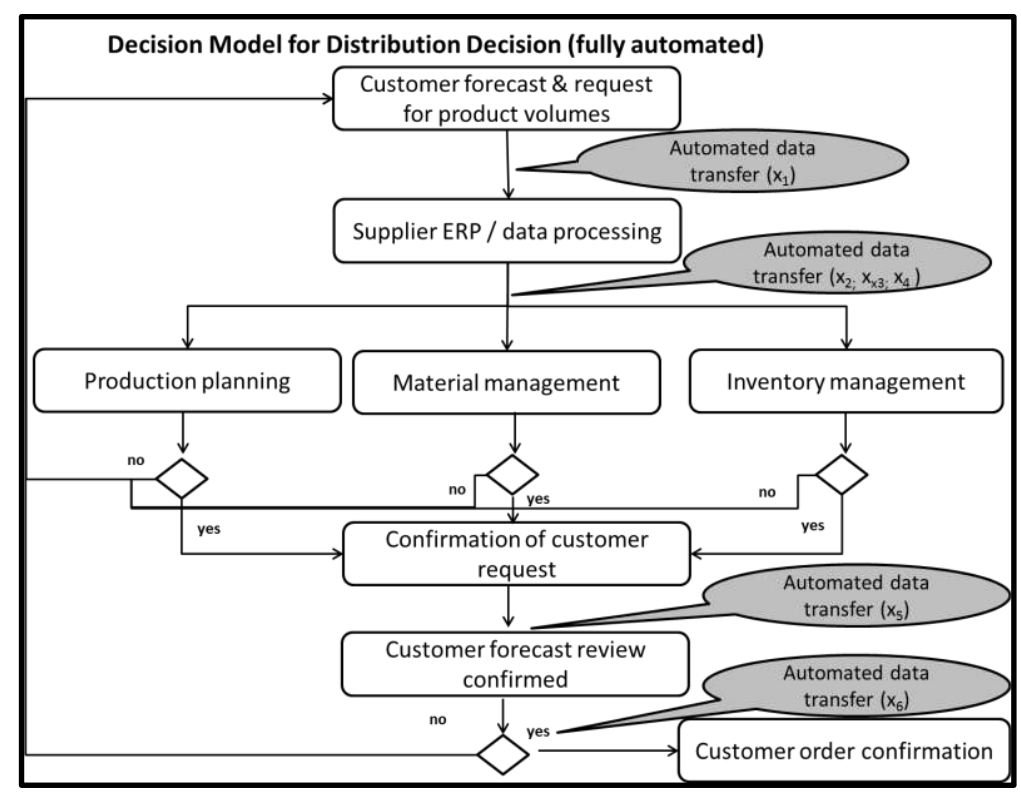

Figure 6: Flow Model with Underlying Variables for a Distribution Decision (designed by the author) 
In the flow chart above, the detailed process with all independent variables is defined. Starting from the customer forecast, as an external event the process will move then into the organization's environment and is becoming an internal process. The availability of the requested products will be checked, if they are on stock. If the product is not available, the production planning and the sourcing process of materials will be steered, either manual or digital. To finalize this process, an order confirmation to the customer is necessary, meaning the process is moving from the internal organizations' environment again external to the customer. In this questionnaire, the relevance and the proportion of digital characteristics will be analyzed. All above-mentioned process steps are manual or digital possible. The explained flow chart is the basis for the questionnaire and is in detail available in appendix A "Questionnaire".

\section{Research Findings}

Analyzing the data from the above-presented questionnaire will prove the hypothesis if there is a dependency of the efficiency of strategic decisions and the digital set up for decision making in organizations. Based on 351 requests, feedback of 67 participants of the questionnaire was given, a return rate of 19\%. The age of the participants was from 26 to 67 , on an average of 44.2 years. Asking for the gender, a pattern with a male dominated structure in senior management positions was given - in numbers, $82 \%$ of the answers were male, $18 \%$ were female. The allocation of company size is displayed in table 2 "Organization's Structure" by revenue and employees.

Table 2: Organizations Strucutre

\begin{tabular}{|l|c|c|l|l|c|c|}
\hline \multicolumn{2}{|c|}{ Revenue Distribution (quantity \& percentage rate) } & & \multicolumn{3}{l|}{ Employee Distribution (quantity \& percentage rate) } \\
\hline $0 €$ to 2 mio $€$ & 3 & $4.5 \%$ & & 1 to 20 employees & 5 & $7.5 \%$ \\
\hline over 2 mio $€$ to 10 mio $€$ & 7 & $10.6 \%$ & & 21 to 100 employees & 13 & $19.4 \%$ \\
\hline over 10 mio $€$ to 50 mio $€$ & 12 & $18.2 \%$ & & 101 to 300 employees & 6 & $9.0 \%$ \\
\hline over 50 mio $€$ to 200 mio $€$ & 12 & $18.2 \%$ & & 301 to 1.000 employees & 10 & $14.9 \%$ \\
\hline over 200 mio $€$ to 1.000 mio $€$ & 16 & $24.2 \%$ & & 1001 to 10.000 employees & 19 & $28.4 \%$ \\
\hline over 1.000 mio $€$ & 16 & $24.2 \%$ & over 10.000 employees & 14 & $20.9 \%$ \\
\hline Total & 66 & $100.0 \%$ & Total & 67 & $100.0 \%$ \\
\hline
\end{tabular}

Starting the analysis from an overall view, question 11.a. will give a major first impression of digitalization effects in the supply chain process. "Agreement" to the statement of "process efficiency by digitalization" is given by 56.9\%, "Disagreement" is answered by $23.1 \%$. This analysis shows a strong trend in organizations toward digitalization and the attention for it. The correlation of "Agreement" to "company size" shows a constant pattern over all company sizes. Hence all organizations are focused on the topic digitalization and agree to an improvement for digitalization. The disagreement rate is only between $21 \%$ and $33 \%$ for all organizations.

Analyzing the process in detail, the author will start from the first step, with the incoming customer order. An overview over the typical statistical key figures is displayed in table 3 "Statistical Evaluation of the Questionnaire". Comparing the individual process steps, outbound data from customers (forecasts) shows the smallest digital characteristics with the highest rate of a manual process. Once the data are in the organization, an increase of digital processing is obvious which is shown with an increased agreement of a digital workflow. Material management is showing an increased mean compared to customer forecast, but lower than the remaining process steps. This trend is ongoing to production planning and inventory management. The climax mean is shown in the process step of customer order confirmation, with a value of 3.39. The overall process is rated with a mean of only 2.8 , which interprets that interviewees have a less opinion of their entire process compared to each single process step. The same trend is shown in the "b-section" of all questions, where interviewee had to evaluate the decision type (automated vs. decision support) für each process step. Despite the same trend between "a- and b-section" of questions 3. to 8., the "a-section" answers are showing a higher mean per each question. This shows that the first step of digitalization is realized is many organizations, but the full effect of digitalization with autonomous processes is not realized yet. The correlation of a-section with b-section (questions 3 to 8) exhibit an value of 0.9, which means, that a more digital process supports an automated decision making process. It seems, that digitalization of processes is the foundation for the next development step of autonomous decision making of these processes. 
Table 3: Statistical Evaluation of the Questionnaire

\begin{tabular}{|c|c|c|c|c|c|c|c|c|c|c|c|c|c|c|c|c|c|c|c|c|}
\hline 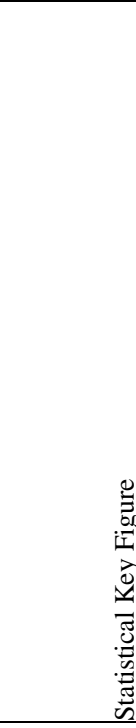 & 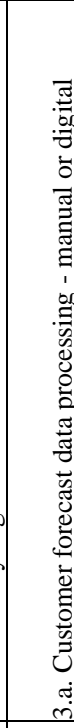 & 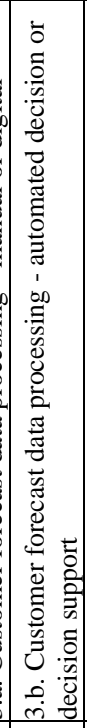 & 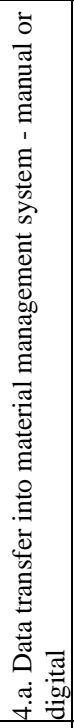 & 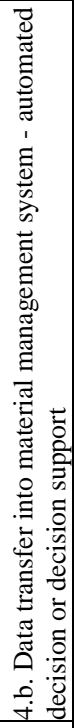 & 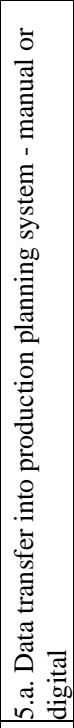 & 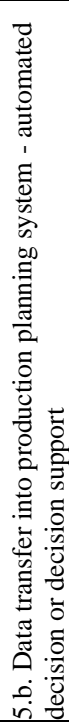 & 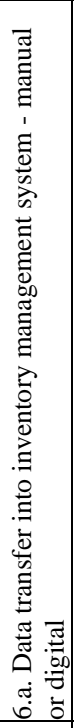 & 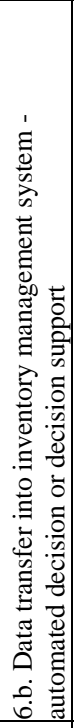 & 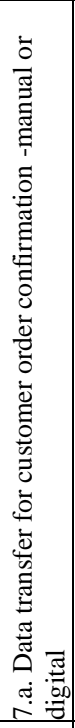 & 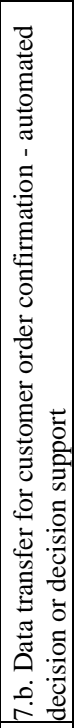 & 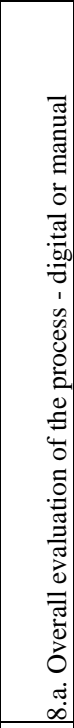 & 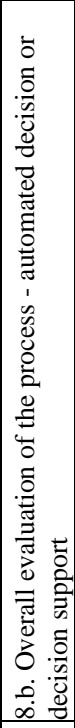 & 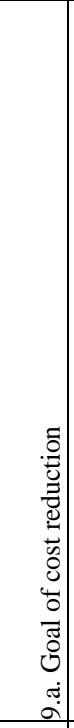 & 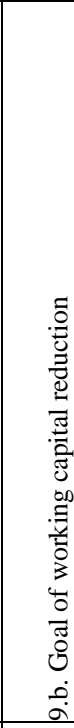 & 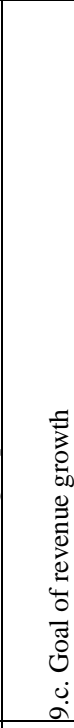 & 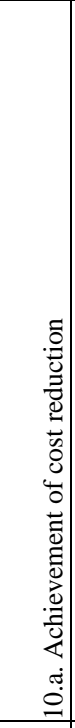 & 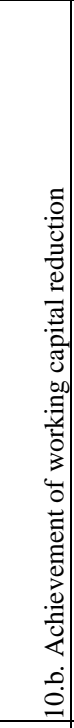 & 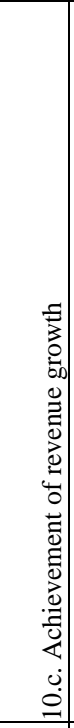 & 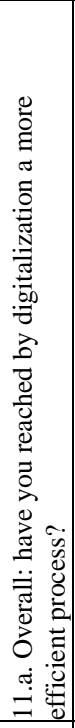 & 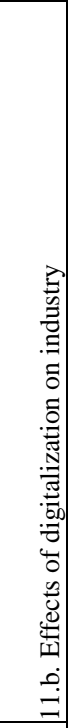 \\
\hline Maximum & 5 & 4 & 5 & 5 & 5 & 5 & 5 & 5 & 5 & 5 & 5 & 4 & 4 & 5 & 5 & 5 & 5 & 5 & 5 & 5 \\
\hline Mean & 2.68 & 1.92 & 2.82 & 2.47 & 3.00 & 2.58 & 3.08 & 2.69 & 3.39 & 3.03 & 2.80 & 2.33 & 1.82 & 2.09 & 2.55 & 2.72 & 2.84 & 2.94 & 2.57 & 3.26 \\
\hline Stand.Dev. & 1.14 & 0.97 & 1.35 & 1.32 & 1.37 & 1.38 & 1.45 & 1.39 & 1.29 & 1.28 & 0.96 & 0.88 & 0.93 & 1.08 & 1.18 & 0.96 & 0.96 & 1.13 & 1.13 & 1.29 \\
\hline Variance & 1.30 & 0.93 & 1.81 & 1.73 & 1.88 & 1.90 & 2.10 & 1.94 & 1.66 & 1.63 & 0.93 & 0.78 & 0.86 & 1.17 & 1.39 & 0.92 & 0.93 & 1.28 & 1.28 & 1.66 \\
\hline Median & 3 & 2 & 3 & 2 & 3 & 2 & 3 & 3 & 3 & 3 & 3 & 2 & 2 & 2 & 2 & 3 & 3 & 3 & 2 & 3 \\
\hline Mode & 3 & 1 & 2 & 1 & 2 & 1 & 5 & 1 & 3 & 4 & 2 & 2 & 1 & 1 & 2 & 3 & 3 & 3 & 2 & 3 \\
\hline
\end{tabular}

Focused on the objectives of digitalization of decision making, cost reduction is the key focus in organizations with a value of $77.3 \%$ agreement, followed by working capital reduction with a value of $70.3 \%$ and revenue growth with a value of $53.0 \%$. This result shows a clear target of digitalization for organizations and their managers. The further effects of this trend on organizations should be analyzed in a further research because it implies a change in organizational structures. Achievements of these objectives are on a lower level, which exhibits that digitalization is in the scope of management but not fully executed yet. Achievement ratio of cost reduction is $44.6 \%$, working capital reduction $35.9 \%$ and revenue growth is $36.9 \%$. The overall achievement of digital decisions in organizations is on a level of $56.9 \%$; undecided is $20.0 \%$, hence a minority evaluate digitalization, not as an efficiency possibility in organizations. The correlation of organizations which have a digital supply chain flow (question 8.a.) and a more efficient supply chain workflow (question 11.a.) is 0.54 . It shows a relation between digitalization and increased efficiency in strategic decisions.

\section{Conclusion}

The impact of digitalization on decision making is given. Referring to, the theoretical view, the type of decision making vary from a rational to an emotional approach. Digitalization will move decision making by cyber systems from emotional to rational decisions, based on algorithmic models. The idea to reach maximum utility, based on discussions from early economists to von Neumann/Morgenstern, seems to be the first time realistic, in the era of automated decisions. Emotions and side effects, which influences decision making will be ongoing eliminated by progressed digitalization.

Summing up the questionnaire results for digital decision making in organizations, the SCOR model as a strategic business case for decisions is well known by managers. The importance of digitalization is given by high involvement of interviewees and high-quality answers including the high interest of results. Digitalization is not a matter of size, all organizations are focused on this topic with a different pattern of progress. Depending on industries and customer approach, digitalization has a diverse status in organizations. Mainly driven by costs, working capital and additional 
revenue opportunities are the main motivators for them. This survey only contributes a small piece of insights into the new era of digitalization, but fits into the pattern, that digitalization is on the agenda of every organization and will influence their next strategic steps. To analyze the massive effect of digitalization on organizations further research has to be done in different areas of science. This paper highlighted only one small piece, with expected results, that digitalization will support the strategic decision making of organizations.

\section{References}

- Bamberg G. \& Coenenberg A. \& Krapp M., 2012. Betriebswirtschaftliche Entscheidungslehre. München: Verlag Franz Vahlen Crossref

- Bauer W. \& Hämmerle M. \& Schlund S. \& Vocke C., 2015. Transforming to a hyper-connected society and economy - towards an "Industry 4.0". Science direct, Procedia Manufacturing 3 ( 2015 ) 417 - 424, Elsevier Crossref

- BDI Research. 2015. Die digitale Transformation der Industrie; BDI - Bundesverband der deutschen Industrie

- Bopp F. 2010. Rapid Manufacturing: Zukünftige Wertschöpfungsmodelle durch generative Fertigungsverfahren. Hamburg; Diplomica Verlag

- Bolstorff P. \& Rosenbaum R. 2007. Supply Chain Excellence. New York. Amacom

- Brynjolfsson E. \& McAfee A., 2014. The Second Machine Age. New York: W.W. Norton \& Company

- Chiu C. 2014. What can crowdsourcing do for decision support? Decision Support Systems 65 (2014) 40 - 49 ; Elsevier Crossref

- Collin J., 2015. IT Leadership in Transition - The Impact of Digitalization on Finnish Organizations. Helsinki: Science \& Technology

- Fichman R. \& Dos Santos B. \& Zheng Z., 06/2014. Digital Innovation as a Fundamental and Powerful Concept in the Information Systems Curriculum. MIS Quarterly Vol. 38 No. 2, pp. 329-353

- Gigerenzer G. \& Selten R. 2001. Bounded Rationality - The Adaptive Toolbox. Cambridge: MIT Press

- Goes P. 07/2014. Big Data and IS Research. MIS Quarterly Vol. 38 No. 3, pp. 3-8

- Jähnchen S. 08/2015. Von Big Data zu Smart Data. Smart Data Newsletter. Vol. 1

- Kahneman D., 2011. Thinking, Fast and Slow. UK: Penguin Random House

- Kahneman D. \& Tversky A., 1974. Judgment Under Uncertainty: Heuristics and Biases. Science, New Series, Vol. 184

- Kreutzer R. \& Land KH. 2015. Digital Darwinism - Branding and Business Models in Jeopardy. Berlin. Springer Verlag

- Laux H. \& Gillenkirch R. \& Schenk-Mathes H., 2014. Entscheidungstheorie. Berlin; Heidelberg: Springer Verlag $\underline{\text { Crossref }}$

- Lee J. \& Kao H. \& Yang S., 2014. Service innovation and smart analytics for Industry 4.0 and big data $\underline{\text { Crossref }}$

- Environment. Science direct, Procedia CIRP 16 ( 2014 ) 3 - 8: Elsevier

- March J. \& Simon H.A., 1997. Organizations. Cambrigde and Oxford: Blackwell

- Neumann von, J. \& Morgenstern O., 1944. Theory of Games and Economic Behaviour. Princeton: University Press

- Picot A. \& Reichwald R. \& Wigand R. 2001. Die grenzenlose Unternehmung. München. Gabler Verlag Crossref

- Porter M.E., 11/2014. How Smart, Connected Products Are Transforming Competition. Harward Business Review Reprint R1411C, pp. 3-22

- Simon H.A., 1997. Administrative Behaviour. New York: The Free Press

- Spath D., 2013. Produktionsarbeit der Zukunft - Industrie 4.0. Fraunhofer IAO; Stuttgart, Fraunhofer IRB-Verlag,

- Sußner C. \& Kuckartz U. 2005. Das Experteninterview in der Bildungsforschung. Phillips-Universität Marburg. Fachbereich ErziehungswissenschaftenWannenwetsch H. 2007. Integrierte Materialwirtschaft und Logistik. Neustadt: Springer Verlag

- Westerman G. \& Bonnet D. \& McAfee A., 2014. Leading Digital. Boston: Harvard Business School Publishing

- Wochnik L., 2014. Die Steigerung des Unternehmenswertes durch Supply Chain Management. Hamburg: Igel Verlag RWS

- Zelinski P., 02/2016. Where 4.0 Might Go. [Online] http://www.mmsonline.com/ [Accessed 10.04.2016] 


\section{Appendix A: "Questionnaire"}

1. Interviewee
a. Age:
b. Gender:
c. Job title:

2. Interviewee Organization
a. Industry:
b. Company size by revenue:
c. Company size by employees:

3. Customer forecast data for the supply chain process ( $\mathrm{x} 1)$

a. How do you process your customer forecast data for the supply chain workflow?

\begin{tabular}{|c|c|c|c|c|}
\hline Manual & More Manual & Balanced & More Digital & Digital \\
\hline 1 & 2 & 3 & 4 & 5 \\
\hline
\end{tabular}

b. Is the processing of these customer forecast data for supply chain a completely automated decision or a decision support process?

\begin{tabular}{|c|c|c|c|c|}
\hline $\begin{array}{c}\text { Decision } \\
\text { Support }\end{array}$ & $\begin{array}{c}\text { More Decision } \\
\text { Support }\end{array}$ & Balanced & $\begin{array}{c}\text { More Automated } \\
\text { Decision }\end{array}$ & $\begin{array}{c}\text { Automated } \\
\text { Decision }\end{array}$ \\
\hline 1 & 2 & 3 & 4 & 5 \\
\hline
\end{tabular}

c. Any comments on data delivery on customer forecast?

d. How difficult was to answer the question "customer forecast data for supply chain"?

\begin{tabular}{|c|c|c|c|c|}
\hline Easy & Partly Easy & Undecided & Partly Difficult & Difficult \\
\hline 1 & 2 & 3 & 4 & 5 \\
\hline
\end{tabular}

4. Data transfer into the material management system (x2)

a. How do you transfer the customer data into your material management system?

\begin{tabular}{|c|c|c|c|c|}
\hline Manual & More Manual & Balanced & More Digital & Digital \\
\hline 1 & 2 & 3 & 4 & 5 \\
\hline
\end{tabular}

b. Is the processing in the material management system a completely automated decision or a decision support process?

\begin{tabular}{|c|c|c|c|c|}
\hline $\begin{array}{c}\text { Decision } \\
\text { Support }\end{array}$ & $\begin{array}{c}\text { More Decision } \\
\text { Support }\end{array}$ & Balanced & $\begin{array}{c}\text { More Automated } \\
\text { Decision }\end{array}$ & $\begin{array}{c}\text { Automated } \\
\text { Decision }\end{array}$ \\
\hline 1 & 2 & 3 & 4 & 5 \\
\hline
\end{tabular}

c. Any comments on data transferring into the material management system?

d. How difficult was to answer the question "data transfer into material management system"?

\begin{tabular}{|c|c|c|c|c|}
\hline Easy & Partly Easy & Undecided & Partly Difficult & Difficult \\
\hline 1 & 2 & 3 & 4 & 5 \\
\hline
\end{tabular}

5. Data transfer into the production planning system (x3)

a. How do you transfer the data into your production planning system?

\begin{tabular}{|l|c|c|c|c|}
\hline Manual & More Manual & Balanced & More Digital & Digital \\
\hline
\end{tabular}


Steffen Hossfeld

The Advantage of Digital Decision Making for Strategic Decisions - Proofed by a Supply Chain Chase

\begin{tabular}{|l|l|l|l|l|}
\hline 1 & 2 & 3 & 4 & 5 \\
\hline
\end{tabular}

b. Is the processing in the production planning system a completely automated decision or a decision support process?

\begin{tabular}{|c|c|c|c|c|}
\hline $\begin{array}{c}\text { Decision } \\
\text { Support }\end{array}$ & $\begin{array}{c}\text { More Decision } \\
\text { Support }\end{array}$ & Balanced & $\begin{array}{c}\text { More Automated } \\
\text { Decision }\end{array}$ & $\begin{array}{c}\text { Automated } \\
\text { Decision }\end{array}$ \\
\hline 1 & 2 & 3 & 4 & 5 \\
\hline
\end{tabular}

c. Any comments on data transferring into the production planning system?

d. How difficult was to answer the question "data transfer into production planning system"?

\begin{tabular}{|c|c|c|c|c|}
\hline Easy & Partly Easy & Undecided & Partly Difficult & Difficult \\
\hline 1 & 2 & 3 & 4 & 5 \\
\hline
\end{tabular}

6. Data transfer into the inventory management system (x4)

a. How do you transfer the data into your inventory management system?

\begin{tabular}{|c|c|c|c|c|}
\hline Manual & More Manual & Balanced & More Digital & Digital \\
\hline 1 & 2 & 3 & 4 & 5 \\
\hline
\end{tabular}

b. Is the processing in the inventory management system a completely automated decision or a decision support process?

\begin{tabular}{|c|c|c|c|c|}
\hline $\begin{array}{c}\text { Decision } \\
\text { Support }\end{array}$ & $\begin{array}{c}\text { More Decision } \\
\text { Support }\end{array}$ & Balanced & $\begin{array}{c}\text { More Automated } \\
\text { Decision }\end{array}$ & $\begin{array}{c}\text { Automated } \\
\text { Decision }\end{array}$ \\
\hline 1 & 2 & 3 & 4 & 5 \\
\hline
\end{tabular}

c. Any comments on data transferring into the inventory management system?

d. How difficult was to answer the question "data transfer into production planning system"?

\begin{tabular}{|c|c|c|c|c|}
\hline Easy & Partly Easy & Undecided & Partly Difficult & Difficult \\
\hline 1 & 2 & 3 & 4 & 5 \\
\hline
\end{tabular}

7. Data transfer for customer order confirmation (x5)

a. How do you confirm the customer order?

\begin{tabular}{|c|c|c|c|c|}
\hline Manual & More Manual & Balanced & More Digital & Digital \\
\hline 1 & 2 & 3 & 4 & 5 \\
\hline
\end{tabular}

b. Is the process of customer order confirmation a completely automated decision or a decision support process?

\begin{tabular}{|c|c|c|c|c|}
\hline $\begin{array}{c}\text { Decision } \\
\text { Support }\end{array}$ & $\begin{array}{c}\text { More Decision } \\
\text { Support }\end{array}$ & Balanced & $\begin{array}{c}\text { More Automated } \\
\text { Decision }\end{array}$ & $\begin{array}{c}\text { Automated } \\
\text { Decision }\end{array}$ \\
\hline 1 & 2 & 3 & 4 & 5 \\
\hline
\end{tabular}

c. Any comments on customer order confirmation? 
Steffen Hossfeld

The Advantage of Digital Decision Making for Strategic Decisions - Proofed by a Supply Chain Chase

d. How difficult was to answer the question "customer order confirmation"?

\begin{tabular}{|c|c|c|c|c|}
\hline Easy & Partly Easy & Undecided & Partly Difficult & Difficult \\
\hline 1 & 2 & 3 & 4 & 5 \\
\hline
\end{tabular}

8. Overall evaluation of the entire process (x6)

a. How do you evaluate the digitalization of your entire supply chain process overall?

\begin{tabular}{|c|c|c|c|c|}
\hline Manual & More Manual & Balanced & More Digital & Digital \\
\hline 1 & 2 & 3 & 4 & 5 \\
\hline
\end{tabular}

b. Is the entire supply chain process a completely automated decision or a decision support process?

\begin{tabular}{|c|c|c|c|c|}
\hline $\begin{array}{c}\text { Decision } \\
\text { Support }\end{array}$ & $\begin{array}{c}\text { More Decision } \\
\text { Support }\end{array}$ & Balanced & $\begin{array}{c}\text { More Automated } \\
\text { Decision }\end{array}$ & $\begin{array}{c}\text { Automated } \\
\text { Decision }\end{array}$ \\
\hline 1 & 2 & 3 & 4 & 5 \\
\hline
\end{tabular}

c. Any comments on overall supply chain process?

d. How difficult was to answer the question "overall evaluation of the supply chain process"?

\begin{tabular}{|c|c|c|c|c|}
\hline Easy & Partly Easy & Undecided & Partly Difficult & Difficult \\
\hline 1 & 2 & 3 & 4 & 5 \\
\hline
\end{tabular}

9. Please evaluate your goal for automation of the supply chain process? (yi)

\begin{tabular}{|c|c|c|c|c|c|c|}
\hline a. & Reduction of costs $\left(\mathrm{y}_{1}\right)$ & Fully Agree & Agree & Undecided & Disagree & $\begin{array}{c}\text { Fully } \\
\text { Disagree }\end{array}$ \\
\hline & & 1 & 2 & 3 & 4 & 5 \\
\hline \multirow[t]{2}{*}{ b. } & $\begin{array}{l}\text { Reduction of working } \\
\text { capital }\left(\mathrm{y}_{2}\right)\end{array}$ & Fully Agree & Agree & Undecided & Disagree & $\begin{array}{c}\text { Fully } \\
\text { Disagree }\end{array}$ \\
\hline & & 1 & 2 & 3 & 4 & 5 \\
\hline \multirow[t]{2}{*}{ c. } & Growth of revenue $\left(\mathrm{y}_{3}\right)$ & Fully Agree & Agree & Undecided & Disagree & $\begin{array}{c}\text { Fully } \\
\text { Disagree }\end{array}$ \\
\hline & & 1 & 2 & 3 & 4 & 5 \\
\hline \multirow[t]{2}{*}{ d. } & Others: & Fully Agree & Agree & Undecided & Disagree & $\begin{array}{c}\text { Fully } \\
\text { Disagree }\end{array}$ \\
\hline & & 1 & 2 & 3 & 4 & 5 \\
\hline
\end{tabular}

10. Please evaluate the achievement of your goals in your supply chain process? (yi)

\begin{tabular}{|l|l|c|c|c|c|c|c|}
\hline a. & $\begin{array}{l}\text { Reduction of costs } \\
\left(\mathrm{y}_{1}\right)\end{array}$ & Fully Agree & Agree & Undecided & Disagree & $\begin{array}{c}\text { Fully } \\
\text { Disagree }\end{array}$ \\
\hline b. & $\begin{array}{l}\text { Reduction of } \\
\text { working capital }\left(\mathrm{y}_{2}\right)\end{array}$ & Fully Agree & Agree & Undecided & Disagree & $\begin{array}{c}\text { Fully } \\
\text { Disagree }\end{array}$ \\
\hline & & 1 & 2 & 3 & 4 & 5 \\
\hline c. & $\begin{array}{l}\text { Growth of revenue } \\
\left(\mathrm{y}_{3}\right)\end{array}$ & Fully Agree & Agree & Undecided & Disagree & $\begin{array}{c}\text { Fully } \\
\text { Disagree }\end{array}$ \\
\hline & & 1 & 2 & 3 & 4 & 5 \\
\hline d. & Others: & & Fully Agree & Agree & Undecided & Disagree & $\begin{array}{c}\text { Fully } \\
\text { Disagree }\end{array}$ \\
\hline & & 1 & 2 & 3 & 4 & 5 \\
\hline
\end{tabular}


Steffen Hossfeld

The Advantage of Digital Decision Making for Strategic Decisions - Proofed by a Supply Chain Chase

11. Overall evaluation: have you reached by digitalization of your supply chain a more efficient decision process?

\begin{tabular}{|c|c|c|c|c|}
\hline Fully Agree & Agree & Balanced & Disagree & Fully Disagree \\
\hline 1 & 2 & 3 & 4 & 5 \\
\hline
\end{tabular}

12. What do you think, to what extend digitalization of decision making has a relevance for your industry? Industry:

\begin{tabular}{|c|c|c|c|c|}
\hline Extreme Low & Low & Medium & High & Extreme High \\
\hline 1 & 2 & 3 & 4 & 5 \\
\hline
\end{tabular}

